\title{
On the synthesis of heterocyclic dendrons
}

\author{
Enrique Díez-Barra,* Joaquín C. García-Martínez, Javier Guerra, Valentín Hornillos, \\ Sonia Merino, Riánsares del Rey, René I. Rodríguez-Curiel, Julián Rodríguez-López, \\ Prado Sánchez-Verdú, Juan Tejeda,* and Juan Tolosa
}

Facultad de Química, Universidad de Castilla-La Mancha, 13071 Ciudad Real, Spain

E-mail: Enrique.Diez@uclm.es

Dedicated to Professor Marcial Moreno-Mañas on the occasion of his $60^{\text {th }}$ birthday

(received 20 Dec 01; accepted 28 Jan 02; published on the web 05 Feb 02)

\begin{abstract}
The synthesis of dendrons $\mathbf{1}$ - $\mathbf{7}$ bearing azole (pyrazole, imidazole and 1,2,4-triazole) moieties is described. The synthesis of these compounds was carried out using different approaches: functionalisation of the methylene bridge of bispirazol-1-ylmethane derivates; double Michael addition of 1,2,4-triazole to methyl propiolate, nucleophilic substitution of halide from the corresponding 2,6-dichloro-4-methylpyridine or 1,3-bis(bromomethyl)benzene derivatives, and nucleophilic substitution on $p$-hydroxybenzaldehyde dimethylacetal. Schotten-Baumann reaction with 1,3,5-trischlorocarbonylbenzene and Sonogashira coupling with 1,3,5-triethynylbenzene were used for the synthesis of G0-dendrimers.
\end{abstract}

Keywords: Heterocyclic dendrons, pyrazole, imidazole, 1,2,4-triazole

\section{Introduction}

Metallodendrimers, ${ }^{1}$ i.e. dendrimers that contain metal atoms or cations, constitute a special class of dendrimer whose redox, ${ }^{2}$ catalytic, ${ }^{3}$ ion recognition, ${ }^{4}$ sensor, ${ }^{5}$ and light harvesting ${ }^{6}$ properties are well documented. Metallodendrimers can act as homogeneous catalysts but are significantly larger than reactants and products, a situation that allows membrane separation techniques to be applied. Other advantages of these dendritic catalysts have been demonstrated and are described in the review by van Leeuwen. ${ }^{3 a}$

The active catalytic centre in a metallodendrimer can be situated in three different areas: (i) metal atom as the dendrimer core, (ii) metal atoms in the dendrimer branches, (iii) metal atoms in the periphery. The synthesis of the third type of metallodendrimer may be envisaged by two strategies. Firstly, it is possible to build the dendrimer and then incorporate the metal atoms in the final stage or, secondly, the metal atoms can be incorporated within the molecular fragments used to build the dendrimer. Regardless of the choice of route, it is necessary to obtain appropriate dendrons that have the ability to coordinate the catalytically active metal atom. In 
addition, dendrons have to bear different functional groups as focal points. In terms of complex formation or the coordination of metal atoms, the azoles are excellent candidates due to the presence of lone pairs on the nitrogen atoms ${ }^{7}$ and the possibility of transformation into nucleophilic carbenes. ${ }^{8}$

The preparation of a catalyst with different catalytic centres requires the following: (i) cores with two or more different functional groups, (ii) dendrons with different focal points and (iii) dendrons having different metal atoms. As the first step in the preparation of a multi-centred catalyst we envisaged the synthesis of dendrons bearing different azoles on the periphery and having different focal points.

\section{Results and Discussion}

We describe the preparation of new dendrons bearing 1,2,4-triazole, pyrazole and imidazole systems and having different focal points (Figure 1). These compounds are suitable for the convergent synthesis of dendrimers with peripheral azole moieties.
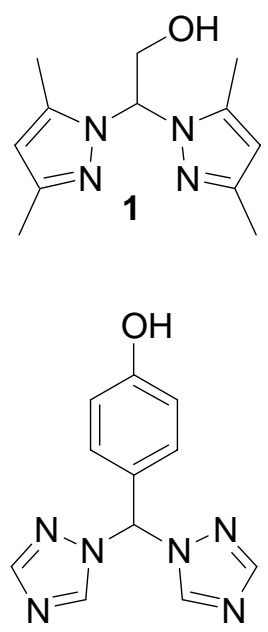

4<smiles>COC(=O)CC(n1cncn1)n1cncn1</smiles>

2

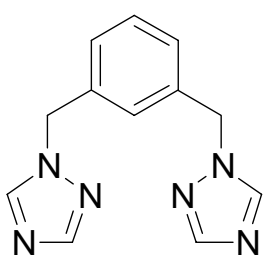

5
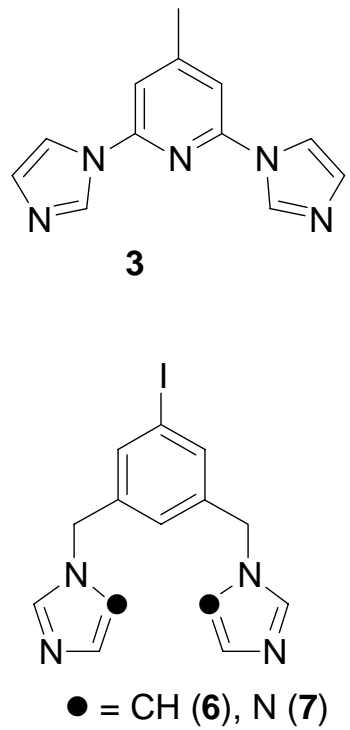

\section{Figure 1}

Compound 1 was prepared from 3,5-dimethylpyrazole by following the route outlined in Scheme 1, the conditions of which are described in the experimental section. Phase Transfer Catalysis (PTC) ${ }^{9}$ alkylation of 3,5-dimethylpyrazole with dichloromethane afforded bis(3,5dimethylpyrazol-1-yl)methane. Deprotonation with $n$-BuLi in THF at low temperature and subsequent reaction with carbon dioxide yielded the corresponding lithium carboxylate. ${ }^{10}$ This lithium salt was reduced with $\mathrm{BH}_{3} \cdot \mathrm{Me}_{2} \mathrm{~S}$ in $\mathrm{THF}^{11}$ (Scheme 1). 

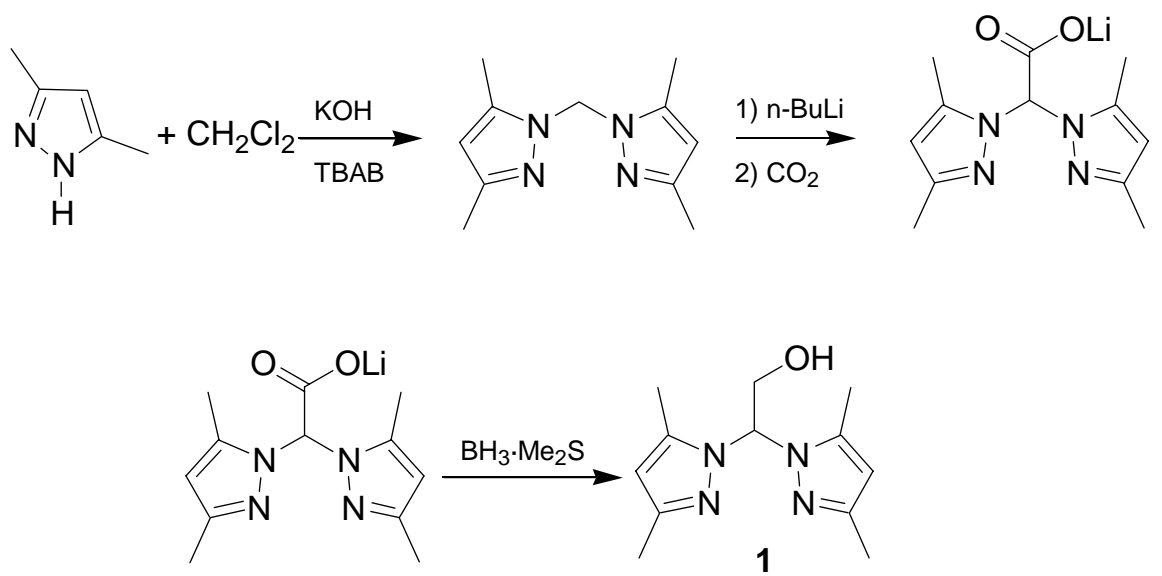

\section{Scheme 1}

Compound 2 was synthesized by a double Michael addition of 1,2,4-triazole to methyl propiolate in THF using the azole/base/Michael acceptor molar ratio indicated (Scheme 2). The use of the appropriate molar ratio guarantees the presence of both the azolate anion and azole, the latter of which protonates the resulting enolate. This situation is necessary to perform the second Michael addition. Although the addition reactions between the 1,2,4-triazole anion and alkyl acrylates, acrylamide and acrylonitrile are known, ${ }^{12}$ results concerning Michael addition to activated alkynes have not been reported to date.

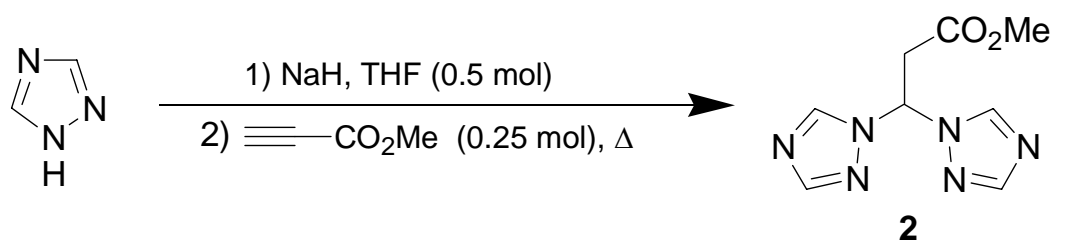

\section{Scheme 2}

2,6-Bis(imidazol-1-yl)-4-methylpyridine (3) was prepared by reaction of imidazole, 2,6dichloro-4-methylpyridine and potassium hydroxide using solid-liquid PTC (without solvent) nucleophilic substitution conditions. The starting material, 2,6-dichloro-4-methylpyridine, was prepared by alkylation ( $n$-BuLi/MeI) of 2,6-dichloropyridine according to a literature procedure $^{13}$ (Scheme 3).

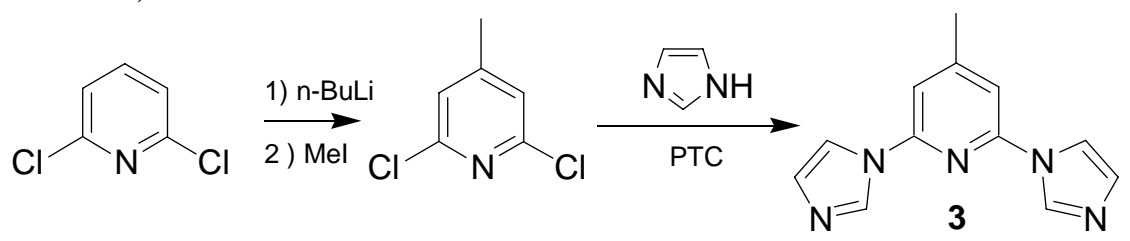

\section{Scheme 3}


This compound is able to form biscarbenes by deprotonation of its corresponding quaternary disalts. The ability of this kind of carbene to form complexes was confirmed by the isolation of a palladium(II) (8) and binuclear mercury(II) and silver(I) (9a and 9b) complexes derived from 2,6-bis(imidazol-1-yl)pyridine ${ }^{14}$ (Scheme 4).
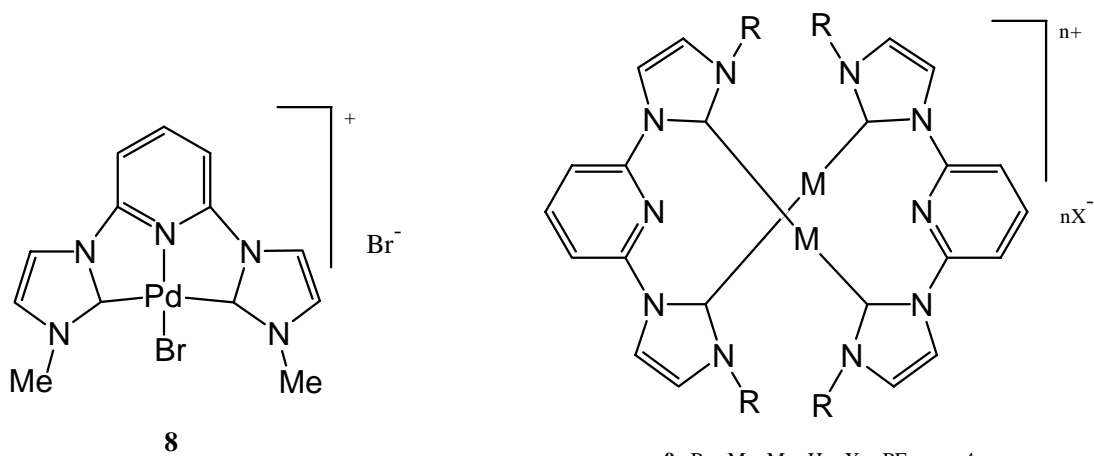

9a $\mathrm{R}=\mathrm{Me}, \mathrm{M}=\mathrm{Hg}, \mathrm{X}=\mathrm{PF}_{6}, \mathrm{n}=4$ 9b $\mathrm{R}=\mathrm{C}_{6} \mathrm{H}_{5} \mathrm{CH}_{2}, \mathrm{M}=\mathrm{Ag}, \mathrm{X}=\mathrm{TfO}, \mathrm{n}=2$

\section{Scheme 4}

The synthesis of 4-[bis(1,2,4-triazol-1-yl)methyl]phenol (4) (Scheme 5) was performed by reaction of $p$-hydroxybenzaldehyde dimethylacetal with 1,2,4-triazole, using $p$-toluenesulfonic acid as catalyst, and required the adaptation of a literature procedure. ${ }^{15}$ In a previous study ${ }^{8}$ the bis(1,2,4-triazol-1-yl)methane system was transformed into a biscarbene and its complex with palladium(II) prepared. Dendron 4 was connected to 1,3,5-trischlorocarbonylbenzene in the presence of 4-aminopyridine following standard procedures. ${ }^{16}$

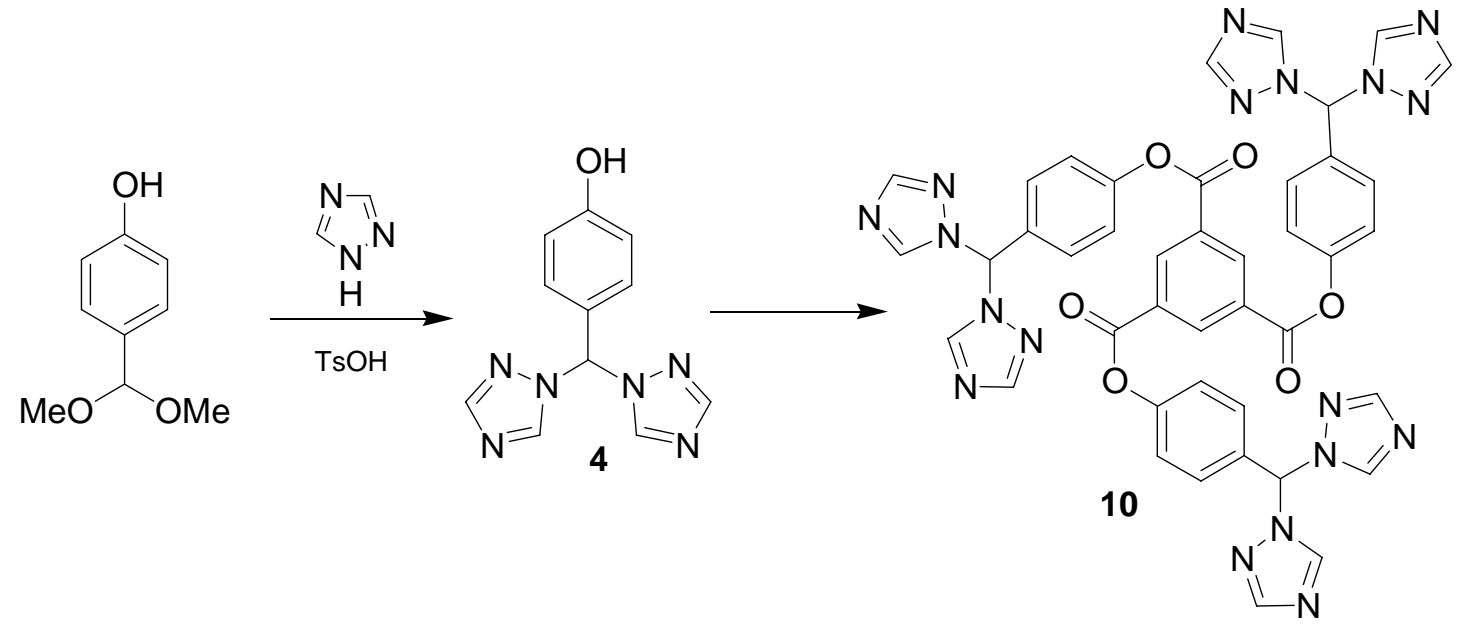

\section{Scheme 5}

The synthesis of dendrons 5, $\mathbf{6}$ and $\mathbf{7}$ was envisaged from the corresponding bromomethylbenzene derivatives by nucleophilic substitution with the appropriate azole anion. 1,3-Bis(bromomethyl)benzene is commercially available, but 1,3-bis(bromomethyl)-5iodobenzene was synthesized from 1,3-dimethyl-5-iodobenzene by radical bromination with 
NBS. Sonogashira reaction of dendron 7 with 1,3,5-triethynylbenzene afforded the corresponding first generation dendrimer (Scheme 6).

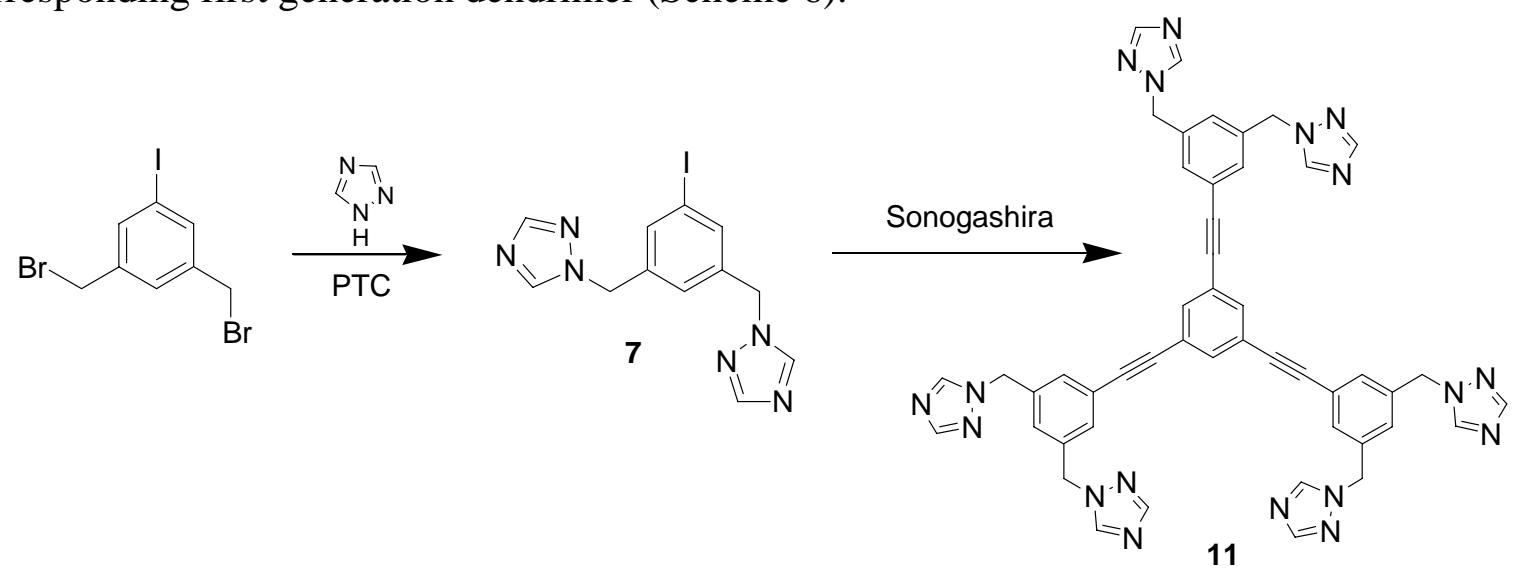

\section{Scheme 6}

All dendrons were fully characterized and their spectroscopic data are collected in the experimental section.

In conclusion, several heterocyclic dendrons were synthesized bearing pyrazole, imidazole and 1,2,4-triazole systems and with different focal points. The possibility of building dendrimers from these systems has also been demonstrated. The ability of this kind of dendron to form complexes with catalytic metal atoms is known. The synthetic routes reported here therefore provide a promising way to develop multi-centred dendrimeric catalysts.

\section{Experimental Section}

General Procedures. Solvents were purified by distillation from appropriate drying reagents before use. Melting points were determined in capillary tubes on a Gallenkamp apparatus and are uncorrected. Elemental analyses were performed on a Perkin-Elmer $2400 \mathrm{CHN}$ microanalyzer. NMR spectra were recorded on a Varian Unity operating at $299.980 \mathrm{MHz}$ for ${ }^{1} \mathrm{H}$ and 75.423 $\mathrm{MHz}$ for ${ }^{13} \mathrm{C}$. Chemical shifts are expressed in parts per million $(\delta)$ relative to TMS as internal standard. The resonances of compounds were assigned by difference NOE and Hetcor experiments.

2,2-Bis(3,5-dimethylpyrazole-1-yl)ethanol (1). A solution of bis(3,5-dimethylpyrazol-1yl)methane $(20 \mathrm{mmol})$ in dry THF $(150 \mathrm{~mL})$ was placed in a $250 \mathrm{~mL}$ Schlenk tube and the solution was cooled to $-70{ }^{\circ} \mathrm{C}$. A $1.6 \mathrm{M}$ solution of $n$-BuLi $(12.5 \mathrm{~mL}, 20 \mathrm{mmol})$ in hexane was added and the solution was stirred for 45 min while $\mathrm{CO}_{2}$ was bubbled through the reaction mixture. The reaction temperature was slowly allowed to reach $0{ }^{\circ} \mathrm{C}$. After $1 \mathrm{~h}$ the solvent was removed under vacuum and a white solid was obtained. This solid, the monohydrated lithium salt, was crystallized from a mixture of THF/hexane. The monohydrated lithium salt (2.75 mmol) was dissolved in dry THF $(150 \mathrm{~mL})$ in a $250 \mathrm{~mL}$ Schlenk tube and a $2.0 \mathrm{M}$ solution of $\mathrm{BH}_{3}$ $\mathrm{Me}_{2} \mathrm{~S}$ (5.5 mL, $11 \mathrm{mmol}$ ) in THF was added. The resulting solution was stirred for $12 \mathrm{~h}$ under 
reflux. The suspension was treated dropwise with acetic acid/water (1:2) until a pH of 5 was obtained. After $1 \mathrm{~h}$ the solution was treated dropwise with a saturated solution of $\mathrm{Na}_{2} \mathrm{CO}_{3}$ to give a $\mathrm{pH}$ of 7 . The mixture was separated and the organic layer dried $\left(\mathrm{MgSO}_{4}\right)$ and concentrated to afford a colourless solid, which was washed with hexane and recrystallized from a mixture of THF/hexane. Yield 46 \%. mp.: 145-148 ${ }^{\circ} \mathrm{C} .{ }^{1} \mathrm{H}$ NMR $\left(\mathrm{CDCl}_{3}, \delta, \mathrm{ppm}\right): 1.94$ (s, 6H, C3CH$)$, 2.21 (s, 6H, C5CH $\mathrm{CH}_{3}, 4.39$ (d, $J=5.8 \mathrm{~Hz}, 2 \mathrm{H}, \mathrm{CH}_{2}$ ), $5.82(\mathrm{~s}, 2 \mathrm{H}, \mathrm{H} 4), 6.28$ (t, $J=5.8 \mathrm{~Hz}, 1 \mathrm{H}$, $\left.\mathrm{CHCH}_{2} \mathrm{OH}\right) .{ }^{13} \mathrm{C} \mathrm{NMR}\left(\mathrm{CDCl}_{3}, \delta\right.$, ppm): 10.5, 13.5, 63.2, 72.5, 106.9, 140.3, 148.2. Anal. Calcd. for $\mathrm{C}_{12} \mathrm{H}_{18} \mathrm{~N}_{4} \mathrm{O}$ (234.30) C, 61.51; H, 7.74; N, 23.91 \%. Found: C, 61.25; H, 7.81; N, 23.82.

Methyl 3,3-bis(1H-1,2,4-triazol-1-yl)propionate (2). To a solution of $1 \mathrm{H}$-1,2,4-triazole (40 mmol) in dry, freshly distilled THF (20 mL), was added sodium hydride (60\%) (20 mmol) in small portions under an inert atmosphere. The mixture was stirred at room temperature for $45 \mathrm{~min}$. A previously prepared solution of methyl propiolate $(10 \mathrm{mmol})$ in dry, freshly distilled THF (10 mL) under an inert atmosphere was then added dropwise by cannula. A reflux condenser was fitted and the mixture was heated under reflux for $24 \mathrm{~h}$. The reaction mixture was allowed to cool down to room temperature and the solvent was removed. The resultant solid was extracted with dichloromethane $(4 \times 20 \mathrm{~mL})$. The solvent was removed to give colourless crystals. Yield: $83 \%$ mp: $117-118{ }^{\circ} \mathrm{C}$ after recrystallization from toluene. ${ }^{1} \mathrm{H} \mathrm{NMR}\left(\mathrm{CDCl}_{3}, \delta\right.$, ppm): 3.71 (s, 3H, $\mathrm{OCH}_{3}$ ), 3.72 (d, $J=7.2 \mathrm{~Hz}, 2 \mathrm{H}, \mathrm{CH}_{2}$ ), 7.09 (t, $J=7.2 \mathrm{~Hz}, 1 \mathrm{H}, \mathrm{CH}_{2} \mathrm{CHTz}_{2}$ ), 7.99 (s, 2H, H3), 8.38 (s, 2H, H5). ${ }^{13} \mathrm{C}$ NMR ( $\left.\delta, p p m\right): 37.9,52.7,67.9,143.1,152.7,168.0$. Anal. Calcd. for $\mathrm{C}_{8} \mathrm{H}_{10} \mathrm{~N}_{6} \mathrm{O}_{2}$ (222.21) C, 43.24; H, 4.54; N, 37.82 \%. Found: C, 43.12; H, 4.50; N, $37.77 \%$.

2,6-Bis(imidazol-1-yl)-4-methylpyridine (3). Imidazole (22 mmol), potassium hydroxide (44 mmol) and TBAB (0.59 mmol) were placed a $100 \mathrm{~mL}$ round-bottomed flask fitted with a reflux condenser and the mixture was stirred for $10 \mathrm{~min}$ at room temperature. 2,6-Dichloro-4methylpyridine $\left(9.2 \mathrm{mmol}\right.$ ) was added and the mixture was stirred for $24 \mathrm{~h}$ at $70{ }^{\circ} \mathrm{C}$. The reaction mixture was extracted with dichloromethane. The solvent was evaporated and crude compound 3 was purified by chromatography $\left(\mathrm{SiO}_{2}\right.$, ethyl acetate/methanol, 9:1) and crystallized from chloroform/diethyl ether. Yield $61 \%$. colourless crystals. mp: $180.5-181.5{ }^{\circ} \mathrm{C} .{ }^{1} \mathrm{H}$ NMR $\left(\mathrm{CDCl}_{3}\right.$, $\delta$, ppm): 2.54 (s, 3H, $\mathrm{CH}_{3}$ ), 7.11 [s, 2H, H3(Py)], 7.23 [t, $\left.J=1.2 \mathrm{~Hz}, 2 \mathrm{H}, H 4(\mathrm{Im})\right], 7.66$ [t, $J=$ $1.5 \mathrm{~Hz}, 2 \mathrm{H}, H 5(\mathrm{Im})], 8.37$ [t, $J=1.1 \mathrm{~Hz}, 2 \mathrm{H}, H 2(\mathrm{Im})] .{ }^{13} \mathrm{C} \mathrm{NMR}\left(\mathrm{CDCl}_{3}, \delta, \mathrm{ppm}\right): 21.6,110.4$, 116.1, 130.9, 135.0, 148.3, 154.1. Anal. Calcd. for $\mathrm{C}_{12} \mathrm{H}_{11} \mathrm{~N}_{5}$ (225.25) C, 63.99; H, 4.92; N, 31.09 \%. Found: C, 63.85; H, 4.90; N, 31.16\%.

4-[Bis(1,2,4-triazol-1-yl)methyl]phenol (4). A mixture of $1 H$-1,2,4-triazole (40 mmol), $p$ hydroxybenzaldehyde dimethylacetal $(20 \mathrm{mmol})$ and $p$-toluenesulfonic acid (1\%) was heated to $120{ }^{\circ} \mathrm{C}$. Further quantities of $p$-toluenesulfonic acid (1\%) were added every 15 min until a reaction time of $270 \mathrm{~min}$ had been reached. The mixture was cooled to room temperature and was extracted with ethyl acetate. The organic solvent was evaporated to give a yellow oil, which was purified by chromatography $\left(\mathrm{SiO}_{2}\right.$, hexane/ethyl acetate, 1:3) and crystallization from ethyl acetate/carbon tetrachloride/diethyl ether/hexane yielded colourless crystals. Yield $48 \%$ mp: 158-60 ${ }^{\circ} \mathrm{C} .{ }^{1} \mathrm{H}$ NMR (d $\mathrm{d}_{6} \mathrm{DMSO}, \delta$, ppm): 6.83 (A of ABq, $J=8.7 \mathrm{~Hz}, 2 \mathrm{H}$ ) and 7.25 (B of ABq, $J=8.7 \mathrm{~Hz}, 2 \mathrm{H})\left(\mathrm{OC}_{6} \mathrm{H}_{4}\right), 8.11(\mathrm{~s}, 2 \mathrm{H})$ and $8.65(\mathrm{~s}, 2 \mathrm{H})[H 3(\mathrm{Tz})$ and $H 5(\mathrm{Tz})], 8.23\left(\mathrm{~s}, 1 \mathrm{H}, \mathrm{CHTz}_{2}\right)$, 9.86 (broad s, $1 \mathrm{H}, \mathrm{OH}) .{ }^{13} \mathrm{C}$ NMR (d $\left.{ }_{6}-\mathrm{DMSO}, \delta, \mathrm{ppm}\right):$ 72.1, 115.6, 123.9, 129.2, 144.5, 152.3, 
158.6. MS (IE), $m / z: 242$ [M] ${ }^{+}, 174,120$, 93, 65. Anal. Calcd. for $\mathrm{C}_{11} \mathrm{H}_{10} \mathrm{~N}_{6} \mathrm{O}$ (242.24): C, 54.24; H, 4.16; N, 34.69 \%. Found: C, 54.26; H, 3.83; N, $35.09 \%$.

1,3-Bis(1,2,4-triazol-1-ylmethyl)benzene (5). A mixture of 1,3-bis(bromomethyl)benzene (15 mmol), 1H-1,2,4-triazole (35 mmol), 40\% aqueous sodium hydroxide (12 mL) and tetrabutylammonium bromide $(1.5 \mathrm{mmol})$ in toluene $(38 \mathrm{~mL})$ was placed in a $100 \mathrm{~mL}$ roundbottomed flask fitted with a reflux condenser. The reaction mixture was heated for $6 \mathrm{~h}$ at $80^{\circ} \mathrm{C}$. The reaction mixture was allowed to cool down to room temperature and the organic material was extracted into dichloromethane $(4 \times 50 \mathrm{~mL})$. The combined organic phase was dried over anhydrous sodium sulphate. The solvent was evaporated and the crude product was purified by column chromatography $\left(\mathrm{SiO}_{2}\right.$, ethyl acetate/methanol, 20:1) and crystallized from ethyl acetate/hexane. Yield: $48 \%$. Colourless crystals. mp: 109-110 ${ }^{\circ} \mathrm{C} .{ }^{1} \mathrm{H} \mathrm{NMR}\left(\mathrm{CDCl}_{3}, \delta\right.$, ppm): $5.34\left(\mathrm{~s}, 4 \mathrm{H}, \mathrm{CH}_{2}\right), 7.17$ [s, $1 \mathrm{H}, H 2\left(\mathrm{C}_{6} \mathrm{H}_{4}\right)$ ], 7.23 [d, $J=7.5 \mathrm{~Hz}, 2 \mathrm{H}, H 4\left(\mathrm{C}_{6} \mathrm{H}_{4}\right)$ and $H 6\left(\mathrm{C}_{6} \mathrm{H}_{4}\right)$ ], 7.39 (t, $\left.J=7.5 \mathrm{~Hz}, 1 \mathrm{H}, H 5\left(\mathrm{C}_{6} \mathrm{H}_{4}\right)\right], 7.97[\mathrm{~s}, 2 \mathrm{H}, \mathrm{H3}(\mathrm{Tz})], 8.11[\mathrm{~s}, 2 \mathrm{H}, \mathrm{H5}(\mathrm{Tz})] .{ }^{13} \mathrm{C}$ NMR $(\delta$, ppm): 53.0, 127.2, 128.0, 129.7, 135.6, 143.1, 152.2. Anal. Calcd. for $\mathrm{C}_{12} \mathrm{H}_{12} \mathrm{~N}_{6}$ (240.27): C, 59.99; H, 5.03; N, $34.98 \%$. Found: C, 59.77; H, 5.05; N, $34.57 \%$.

1,3-Bis(bromomethyl)-5-iodobenzene. To a mixture of 5-iodo-m-xylene $(10 \mathrm{mmol})$ in acetonitrile $(25 \mathrm{~mL})$ was added $N$-bromosuccinimide $(22 \mathrm{mmol})$. The reaction mixture was stirred and heated under reflux with light irradiation. The progress of the reaction was followed by TLC (hexane) until the starting material had disappeared. The solvent was evaporated and the resultant solid was extracted with carbon tetrachloride $(2 \times 30 \mathrm{~mL})$ in order to remove succinimide, which is not soluble in this solvent. The mixture was filtered and the solvent was removed. The resulting solid product was washed with cold ethanol $(3 \times 20 \mathrm{~mL})$ and then recrystallized from ethanol. Colourless crystals. Yield: $42 \%$. mp: $112-113{ }^{\circ} \mathrm{C} .{ }^{1} \mathrm{H}$ NMR $\left(\mathrm{CDCl}_{3}\right.$, $\delta$, ppm): 4.38 (s, 4H, $\mathrm{CH}_{2}$ ), 7.38 (s, $\left.1 \mathrm{H}, \mathrm{H} 2\right), 7.67$ (s, $\left.2 \mathrm{H}, \mathrm{H} 4\right) .{ }^{13} \mathrm{C}$ NMR ( $\delta$, ppm): 31.3, 94.3, 129.0, 137.8, 140.2. Anal. Calcd. for $\mathrm{C}_{8} \mathrm{H}_{7} \mathrm{Br}_{2} \mathrm{I}$ (389.85): C, 24.65; H, 1.81 \%. Found: C, 24.54; $\mathrm{H}, 1.75 \%$.

1,3-Bis(imidazol-1-ylmethyl)-5-iodobenzene (6). 1,3-Bis(bromomethyl)-5-iodobenzene ( $2.5 \mathrm{mmol}), 1 \mathrm{H}$-imidazole $(5.5 \mathrm{mmol})$, anhydrous potassium carbonate $(5.5 \mathrm{mmol})$, powdered potassium hydroxide $(5.5 \mathrm{mmol})$ and tetrabutylammonium bromide $(0.25 \mathrm{mmol})$ were placed in a $100 \mathrm{~mL}$ round-bottomed flask with toluene $(50 \mathrm{~mL})$ as the solvent. The mixture was heated at $80{ }^{\circ} \mathrm{C}$ for $30 \mathrm{~h}$. The reaction mixture was filtered and the solid residue was extracted with dichloromethane $(3 \times 20 \mathrm{~mL})$. The combined organic phases were dried over anhydrous sodium sulphate. The solvent was evaporated and the product was purified by column chromatography on silica gel. Elution with ethyl acetate/methanol (12:1) afforded the pure product as a colourless solid. Yield: $37 \%$. mp: $165-166{ }^{\circ} \mathrm{C}$ after recrystallization from ethyl acetate. ${ }^{1} \mathrm{H}$ NMR $\left(\mathrm{CDCl}_{3}\right.$, $\delta$, ppm): 5.05 (s, 4H, $\mathrm{CH}_{2}$ ), 6.84 [s, $1 \mathrm{H}, H 2\left(\mathrm{C}_{6} \mathrm{H}_{3}\right)$ ], 6.88 [s, 2H, H5(Im)], 7.12 (s, 2H, H3(Im)], 7.44 [s, $\left.2 \mathrm{H}, \mathrm{H} 4\left(\mathrm{C}_{6} \mathrm{H}_{3}\right)\right], 7.54$ [s, $\left.2 \mathrm{H} \mathrm{H}_{2}(\mathrm{Im})\right] .{ }^{13} \mathrm{C}$ NMR $(\delta, \mathrm{ppm}): 49.6,95.3,119.1,125.0,130.2$, 135.9, 137.3, 139.2. MS (IE), m/z: 364.0 [M] ${ }^{+}$, 296.0, 255.9, 169.1, 143.1, 103.0, 77.0. Anal. Calcd. for $\mathrm{C}_{14} \mathrm{H}_{13} \mathrm{IN}_{4}$ (364.18): C, 46.17; H, 3.60; N, 15.38 \%. Found: C, 46.19; H, 3.71; N, $15.15 \%$.

1,3-Bis(1,2,4-triazol-1-ylmethyl)-5-iodobenzene (7). 1,3-Bis(bromomethyl)-5-iodobenzene (3 mmol), $1 \mathrm{H}-1,2,4$-triazole $(7 \mathrm{mmol})$, anhydrous potassium carbonate $(7 \mathrm{mmol})$, powdered potassium hydroxide $(7 \mathrm{mmol})$ and tetrabutylammonium bromide $(0.3 \mathrm{mmol})$ were placed in a 
$50 \mathrm{~mL}$ round-bottomed flask. The mixture was heated under reflux in toluene $(30 \mathrm{~mL})$ for $38 \mathrm{~h}$ and the crude reaction mixture was filtered. The solid residue was extracted with dichloromethane $(4 \times 25 \mathrm{~mL})$. The combined organic phases were dried over anhydrous sodium sulphate. The solvent was evaporated and the product was purified by chromatography on silica gel. Elution with ethyl acetate/methanol (19:1) afforded the pure product as a colourless solid. Yield: 50 \%. mp: $156-158{ }^{\circ} \mathrm{C}$ after recrystallization from ethyl acetate/hexane. ${ }^{1} \mathrm{H}$ NMR $\left(\mathrm{CDCl}_{3}\right.$, $\delta, \mathrm{ppm}): 5.28\left(\mathrm{~s}, 4 \mathrm{H}, \mathrm{CH}_{2}\right), 7.11\left[\mathrm{~s}, 1 \mathrm{H}, \mathrm{H} 2\left(\mathrm{C}_{6} \mathrm{H}_{3}\right)\right], 7.57$ [s, 2H, H4( $\left.\left.\mathrm{C}_{6} \mathrm{H}_{3}\right)\right], 7.99$ [s, 2H, $H 3(\mathrm{Tz})$ ], 8.12 [s, 2H, H5(Tz)]. ${ }^{13} \mathrm{C}$ NMR ( $\delta$, ppm): 52.2, 95.2, 126.5, 136.9, 137.6, 143.2, 152.6. Anal. Calcd. for $\mathrm{C}_{12} \mathrm{H}_{11} \mathrm{IN}_{6}$ (366.16): C, 39.36; H, 3.03; N, 22.95 \%. Found: C, 39.29; H, 3.04; N, $22.60 \%$.

Tris\{4-[bis(1,2,4-1H-triazol-1-yl)methyl]phenyl\}benzene-1,3,5-tricarboxylate (10). A mixture of dendron 4 (1.65 mmol) and 4-dimethylaminopyridine (1.8 mmol) was dissolved in anhydrous THF $(10 \mathrm{~mL})$ under argon in a $100 \mathrm{~mL}$ Schlenk tube. After $5 \mathrm{~min}$, a solution of 1,3,5trischlorocarbonylbenzene $(0.5 \mathrm{mmol})$ in anhydrous THF $(5 \mathrm{~mL})$ was added and the reaction mixture was stirred for $2 \mathrm{~h}$ at room temperature. The amine hydrochloride was filtered off and the solvent from the filtrate was evaporated. The solid residue was dissolved in dichloromethane and the solution was washed with water. The organic layer was dried with anhydrous $\mathrm{Na}_{2} \mathrm{SO}_{4}$. The pure product was obtained as colourless crystals after filtration and solvent evaporation. Yield 80\%. mp: $135{ }^{\circ} \mathrm{C}$ (decomposition). ${ }^{1} \mathrm{H}$ NMR ( $\mathrm{d}_{6}$-DMSO, $\delta, \mathrm{ppm}$ ): 7.50 (s, 12H, $\mathrm{OC}_{6} \mathrm{H}_{4}$ ), $8.18(\mathrm{~s}, 6 \mathrm{H})$ and $8.78(\mathrm{~s}, 6 \mathrm{H})[\mathrm{H} 3(\mathrm{Tz})$ and $\mathrm{H5}(\mathrm{Tz})], 8.50\left(\mathrm{~s}, 3 \mathrm{H}, \mathrm{CHTz}_{2}\right), 9.02\left(\mathrm{~s}, 3 \mathrm{H}, \mathrm{C}_{6} \mathrm{H}_{3}\right) .{ }^{13} \mathrm{C}$ NMR (d ${ }_{6}$-DMSO, $\left.\delta, \mathrm{ppm}\right):$ 71.5, 122.4, 129.1, 130.7, 132.1, 135.2, 144.8, 151.1, 152.5, 162.7. MS (FAB, m-nitrobenzylalcohol), $m / z: 883[\mathrm{M}+1]^{+}, 814,545,244$. Anal. Calcd. for $\mathrm{C}_{42} \mathrm{H}_{30} \mathrm{~N}_{18} \mathrm{O}_{6}$ (882.82): C, 57.14; H, 3.42; N, 28.56 \%. Found: C, 57.41; H, 3.38; N, $28.78 \%$.

1,3,5-Tris[3,5-bis(1H-1,2,4-triazol-1-ylmethyl)phenyl]ethynylbenzene (11). A mixture of 1,3,5-triethynylbenzene $(0.167 \mathrm{mmol})$ and 1,3-bis(1H-1,2,4-triazol-1-ylmethyl)-5-iodobenzene (0.5 mmol) was introduced into a flame-dried $25 \mathrm{~mL}$ Schlenk tube under an inert atmosphere. Dry DMF $(10 \mathrm{~mL})$ and dry $\mathrm{NEt}_{3}(0.2 \mathrm{~mL})$ were added to the reaction mixture by syringe. The reaction was stirred until the starting materials had completely dissolved. The reaction mixture was then treated with a catalytic mixture of $\mathrm{PPh}_{3}, \mathrm{CuI}$ and $\mathrm{PdCl}_{2}\left(\mathrm{PPh}_{3}\right)$ 2:1:1, respectively, $(0.05 \mathrm{mmol}, 0.025 \mathrm{mmol}, 0.025 \mathrm{mmol})$. The reaction mixture turned yellow and was stirred at room temperature for $30 \mathrm{~h}$. The progress of the reaction was monitored by TLC. The solvent was removed and the reddish-orange solid was purified by chromatography on silica gel with ethyl acetate/methanol (3:1). The colourless product was recrystallized from methanol. Yield: 51\%. m.p.: 200-201 ${ }^{\circ} \mathrm{C} .{ }^{1} \mathrm{H}$ NMR (d $\mathrm{d}_{6}-\mathrm{DMSO}, \delta$, ppm): 5.46 (s, 12H, $\mathrm{CH}_{2}$ ), 7.30 [s, 3H, H4(branch$\mathrm{C}_{6} \mathrm{H}_{3}$ )], 7.42 [s, 6H, H2(branch- $\mathrm{C}_{6} \mathrm{H}_{3}$ )], 7.77 (s, 3H, Core), 8.02 [s, 6H, H3(Tz)], 8.70 (s, 6H, H5(Tz)]. ${ }^{13} \mathrm{C}$ NMR $\left(\mathrm{d}_{6}-\mathrm{DMSO}, \delta\right.$, ppm): 51.3, 87.9, 90.0, 122.3, 123.3, 128.2, 130.3, 134.1, 137.5, 144.4, 151.9. MS (FAB, m-nitrobenzylalcohol), m/z: $865[\mathrm{M}+1]^{+}$, 796. Anal. Calcd. for $\mathrm{C}_{48} \mathrm{H}_{36} \mathrm{~N}_{18}$ (864.94) C, 66.66; H, 4.19; N, 29.15 \%. Found: C, 66.40; H, 3.98; N, 28.89 \%.

\section{Acknowledgements}


Financial support from the Spanish CICYT (PB97-0425 and 1FD97-0167) is gratefully acknowledged.

\section{References}

1. Newkome, G. R.; He, E.; Moorefield, C. N. Chem. Rev. 1999, 99, 1689.

2. (a) Top. Curr. Chem. 1998, 197. Vögtle, F., Ed.; p 193. (b) Vögtle, F.; Plevoets, M.; Nieger, M.; Azzellini, G. C.; Credi, A.; de Cola, L.; de Marchis, V.; Venturi, M.; Balzani, V. J. Am. Chem. Soc. 1999, 121, 6290.

3. (a) Oosterom, G. E.; Reek, J. N. H.; Kamer, J. N. H.; van Leeuwen, P. W. N. M. Angew. Chem., Int. Ed. 2001, 40, 1828. (b) Astruc D.; Chardac F. Chem. Rev. 2001, 101, 2991. (c) Bourque, S. C.; Alper, H. J. Am. Chem. Soc. 2000, 122, 956. (d) Kleij, A. J.; Gossage, R. A.; Jastrzebski, J. T. B. H.; Boersma, J.; van Koten, G. Angew. Chem., Int. Ed. 2000, 39, 176.

4. Valerio, C.; Alonso, E.; Ruiz, J.; Blais, J. C.; Astruc, D. Angew. Chem., Int. Ed. 1999, 38, 1747.

5. Albert, M.; van Koten, G. Adv. Mater. 1999, 11, 171.

6. (a) Balzani, V.; Campagna, S.; Denti, G.; Juris, A.; Serroni, S.; Venturi, M. Acc. Chem. Res. 1999, 31, 26. (b) Sakamoto, M.; Ueno, A.; Mihara, H. Chem. Eur. J. 2001, 7, 2449.

7. Antiñolo, A.; Carrillo-Hermosilla, F.; Díez-Barra, E.; Fernández-Baeza, J.; FernándezLópez, M.; Lara-Sánchez, A.; Moreno, A.; Otero, A.; Rodríguez, A. M.; Tejeda, J. J. Chem. Soc., Dalton Trans. 1998, 3737 and references cited therein.

8. Bertrand, G.; Díez-Barra, E.; Fernández-Baeza, J.; Gornitzka, H; Moreno, A.; Otero, A.; Rodríguez-Curiel, R. I.; Tejeda, J. Eur. J. Inorg. Chem. 1999, 1965 and references cited therein.

9. Juliá, S.; Sala, P.; del Mazo, J.; Sancho, N.; Ochoa, C.; Elguero, J.; Fayet, J.-P.; Vertut, M.C. J. Heterocycl. Chem. 1982, 19, 1141.

10. Otero, A.; Fernández-Baeza, J.; Tejeda, J.; Antiñolo, A.; Carrilo-Hermosilla, F.; Díez-Barra, E.; Lara-Sánchez, A.; Fernández-López, M.; Lanfranchi, M.; Pellingheli, M. A. J. Chem. Soc., Dalton Trans. 1999, 3573.

11. Otero, A.; Fernández-Baeza, J.; Tejeda, J.; Antiñolo, A.; Carrilo-Hermosilla, F.; Díez-Barra, E.; Lara-Sánchez, A.; Fernández-López, M. J. Chem. Soc., Dalton Trans. 2000, 2367.

12. (a) Horvath, A. Tetrahedron Lett. 1996, 37, 4423. (b) de la Cruz, A.; Elguero, J.; Goya, P.; Martinez, A. J. Heterocycl. Chem. 1988, 25, 225.

13. Radinov, R.; Chanev, C.; Haimova, M. J. Org. Chem. 1991, 56, 4793.

14. (a) Peris, E.; Loch, J. A.; Mata, J.; Crabtree, R. H. Chem. Commun. 2001, 201. (b) Chen, J. C. C.; Lin, I. J. B. J. Chem. Soc., Dalton Trans. 2000, 839. (c) Caballero, A.; Díez-Barra, E.; Jalón, F. A.; Merino, S.; Rodríguez, A. M.; Tejeda, J. J. Organomet. Chem. 2001, 627, 263.

15. Trofimenko, S. J. Am. Chem. Soc. 1970, 92, 5118.

16. Uhrich, K. E.; Fréchet, J. M. J. J. Chem. Soc., Perkin Trans. 1 1992, 1623. 